\title{
IS THIS HOLY RELIC PRESERVED?
}

As a material artefact, the Shroud of Turin should be a fairly simple puzzle to solve. Whether it is really the burial cloth of Jesus Christ isn't a well-posed question scientifically, but - you would think - at least a disproof should be straightforward. And that's how it seemed when a radiocarbon dating study in 1989 reported that the shroud linen dates from around the thirteenth to the fourteenth century ${ }^{1}$. A medieval forgery, then.

But was that tiny sample representative of the whole? Others claimed that the patch tested - a unique event so far, requiring papal approval - was from a later addition. Or maybe a well-documented chapel fire in the sixteenth century, which caused some scorching, reset the clock. Or recent biofilms had disturbed the measurements. It all sounds like special pleading, but a controversial spectroscopic study in 2013 fanned the flames by placing the origin of the shroud back in Roman times ${ }^{2}$.

Then there is the question of how the image of a bearded man became imprinted on the fabric. This is truly strange. There is no sign of pigments or brush strokes: the upper layers of the flax fibres themselves have darkened to reveal the very faint figure, and the colouring can't be bleached or dissolved. Could the discolouration have been produced by mild heating and/or some chemical process, perhaps involving amines or lactic acid in sweat ${ }^{3,4}$ ? Some haven't stopped short of proposing quasi-fantastical (or, if you prefer, divine) release of 'radiant energy' such as X-rays ${ }^{5}$.

It is hard, among all this feverish speculation, for calm science to prevail, especially because no further testing of the shroud - venerated last year by Pope Francis as an 'object of devotion' - has so far been authorized. The latest findings are presented soberly enough, but their reception will surely be considered by true believers to add weight to their case. Botanist Marzia Boi of the University of the Balearic Islands in Palma de Mallorca has re-analysed microscopic images and descriptions of pollen grains found in the shroud and compared them with modern samples 6 . She concludes that the most abundant form of pollen is not, as reported before ${ }^{7}$, from the spiny tumbleweed Gundelia tournefortii found in the Middle East (and used in cooking), but from the Mediterranean Helichrysum genus. The Gundelia plant was touted as a candidate for a 'crown of thorns', but that never seemed very plausible. Helichrysum species (in the Asteraceae, or sunflower, family) are, however, sources of essential oils used in ancient embalming practices.

Other pollen grains, says Boi, correspond to Cistaceae (genus Cistus) and Anacardianceae (genus Pistacia) species as reported previously. These

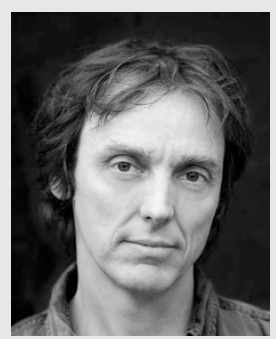

PHILIP BALL

were also sources of balms for funeral and burial in ancient times, according to Roman and Greek writers such as Pliny the Elder and Dioscorides. Extracts of these plants aren't so easily matched to medieval burial practices.

Boi argues that the new identification of Helichrysum pollen suggests that the origins of the shroud "lie in the first century AD" and that the finding "validates the theory that the corpse kept in the shroud received a funeral and burial with all the honour and respect that was customary in the Hebrew tradition." Let the arguments begin.
References

1. Damon, P. E. et al. Nature 337, 611-615 (1989).

2. Fanti, G. \& Gaeta, S. Il mistero della Sindone (Rizzoli, 2013)

3. Rogers, R. N. \& Arnoldi, A. Scientific Method Applied to the Shroud of Turin http://go.nature.com/2oPXw88 (2002).

4. DeSalvo, J. A. Sindon 31, 43-50 (1982).

5. Moran, K. \& Fanti, G. 4th Symp. Sci. Int. du CIELT (Sindone, 2002); http://go.nature.com/2oqwYNR

6. Boi, M. Archaeometry 59, 316-330 (2017)

7. Danin, A., Whanger, A. D., Baruch, U. \& Whanger, M. Flora of the Shroud of Turin (Missouri Botanical Garden, 1999).

\section{Pushing the knowledge of interfaces}

The use of a spectroscopy technique called pump-push-probe electro-absorption provides insight into the energetic landscape of nanostructured donor-acceptor interfaces in bulk-heterojunction organic solar cells.

Natalie Banerji

harge transfer at solid-solid interfaces plays a primary role for solid-state electrochemistry, energy storage, catalysis and photovoltaic energy conversion. It is therefore of utmost importance to understand the behaviour of charges and the electronic landscape near the interface, which can be significantly different from the bulk of the materials. This is particularly challenging when the interface is nanostructured, disordered and buried away from the surface. In this case, more conventional techniques such as electron microscopy, photoelectron spectroscopy, X-ray measurements and even surface-specific nonlinear optical techniques tend to fail. Now, writing in Nature Materials, Andreas Jakowetz and colleagues overcome this limitation by developing a spectroscopic method known as pump-push-probe electroabsorption (PPP-EA), which allows probing the dynamics of photogenerated charges and 